\title{
Iatrogenic Damage to the Periodontium Caused by Exodontic Treatment Procedures: An Overview
}

\author{
Senthil RS Rajan ${ }^{1}$, Khaja Amjad Hussain ${ }^{2, *}$, Bassel Tarakji ${ }^{3}$, Saleh Nasser Azzeghaibi ${ }^{4}$ and \\ Syed Sirajuddin ${ }^{5}$
}

\author{
${ }^{I}$ Department of Periodontology, Rajarajeswari Dental College \& Hospital, Bangalore-560074. Karnataka, India; \\ ${ }^{2}$ Department of Oral-maxillofacial Sciences, Alfarabi College of Dentistry and Nursing, Riyadh, Saudi Arabia; \\ ${ }^{3}$ Department of Oral-maxillofacial Sciences, Alfarabi College of Dentistry and Nursing, Riyadh, Saudi Arabia; \\ ${ }^{4}$ Alfarabi College of Dentistry and Nursing, Riyadh, Saudi Arabia; ${ }^{5}$ Department of Periodontology, Rajarajeswari \\ Dental College \& Hospital, Bangalore-560074. Karnataka, India
}

\begin{abstract}
Dentists encounter a wide range of hard-tissue injuries in practice. Dental extractions are one of the most common procedures in dentistry and may lead to several complications, including oral sinus complications, osteitis, infection, dysesthesia, pain, and bleeding.
\end{abstract}

Keywords: Extractions, iatrogenic, periodontium.

\section{INTRODUCTION}

Dentists come across diverse range of hard-tissue injuries in their practice. One of the most common procedures in dentistry is dental extraction that may lead to several problems, including pain, bleeding, infection, osteitis, oral sinus complications, and dysesthesia [1]. Commonly seen injuries include dento-alveolar trauma and those accidentally caused by the dentists in practice. Extent of tooth impaction, form of tooth angulation, length of roots, patient age, age and capability of the surgeon, occurrence of a cyst or tumor around an impacted third molar, systemic disease or medications that may damage bone strength, preoperative infections in the third molar site, and improper preoperative examination are the factors that influence the occurrence and a etiology of iatrogenic mandibular fractures [2]. When the forces acting on the bone exceed the strength of the bone lead to fracture.

Iatrogenic fractures may take place during the procedure or occur within 4 weeks after the treatment (classified as pathological fractures), and generally are associated with third molar extractions [3]. The mandible is fractured 2-3 times more commonly than other facial bones since it has a reduced amount of bony support [4]. The body of the mandible is naturally strengthened by a system of buttresses extending onto the ramus of the mandible. On the lateral surface, the external oblique ridge extends from the body obliquely upward to the anterior border of the ramus. Although, the medial surface is thinner than the lateral surface, both are composed of dense, thick, and compact cortical bone. The mylohyoid line extends diagonally downward from the area of the third molar and forward to the genial tubercles at the midline. As pressure is localized primarily on

*Address correspondence to this author at the Department of Oralmaxillofacial Sciences, Alfarabi College of Dentistry and Nursing, Riyadh, Saudi Arabia; Tel: 00966227 3151; Fax: 00966232 4580;

E-mail: amjadh@gmail.com the external oblique ridge, it is essential to protect this region during surgery [5]. The fracture occurs mainly due to the location of the third molar, which occupies a large osseous space and thereby weakens the mandibular angle by reducing the cross-sectional area of bone and resulting in the loss of supportive bone, particularly in the external oblique ridge.

Mandibular fractures can be managed by open or closed reduction methods. In closed reduction procedures, to attain adequate occlusion dental wiring or bars are applied to the dental arch. Closed reduction is indicated in non-displaced favorable fractures. The open reduction of mandibular fractures is indicated in displaced unfavorable fractures, multiple fractures, cases in which Inter Maxillary Fixation (IMF) is difficult or contraindicated, and cases in which IMF is avoided to reduce patient discomfort. The terms "favorable" and "unfavorable" are used to describe mandibular angle fractures. The direction of the fracture line affects the resistance to muscle pull. When muscle pull resists the displacement of fragments, the fracture line is considered to be favorable; when muscle pull distracts the fragments away from one another, resulting in displacement, the fracture line is considered to be unfavorable [6].

Teeth along the line of a fracture were previously thought as a potential obstruction to healing due to the possibility of tooth death or earlier infection and the risk of infection transfer via the periodontal membrane.

Injudicious tooth removal can initiate periodontal disease or aggravate an existing pathosis in the vicinity of the extraction. In tooth extraction, some common errors that adversely affect the periodontium

1. Manner in which facial and lingual flaps are raised.

2. Manner in which the teeth are luxated and elevated.

3. Degree of post extraction debridement. 
4. Method in which the wound is closed.

- In most cases creation of flaps is unnecessary, but flaps are necessary to expose the supporting alveolar bone for its reduction, to simplify removal of tooth, or to correct morphologic or pathologic aberrations of the hard and / or soft tissues along with extraction.

- If width and thickness of the band of attached gingiva are normal, gingiva should be preserved and repositioned accurately in its original site and stabilized by careful suturing.

- If the flaps are sutured tightly (Fig. 1) they result in pseudopocket formation, as the connective tissue does not attach to the enamel surface and this also results in an incorrectly positioned band of gingiva which becomes nonfunctional as it has lost part or all of its attachment and has become an exaggerated free gingival margin.

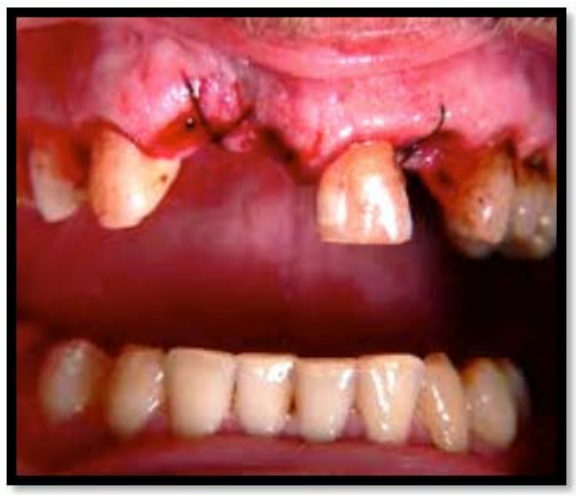

Fig. (1). Flap should be properly sutured.

This situation becomes serious if the original zone of attached gingiva in the vicinity of extraction is minimal or non-existent. If the zone of attached gingiva is more than adequate, or thicker than normal, the entire width of this band should be preserved while raising the flap (Fig. 2). (Internal levelflap procedure should be used in such cases) as it will result in a uniformly thinned flap and improved soft tissue characteristics around the extraction site.

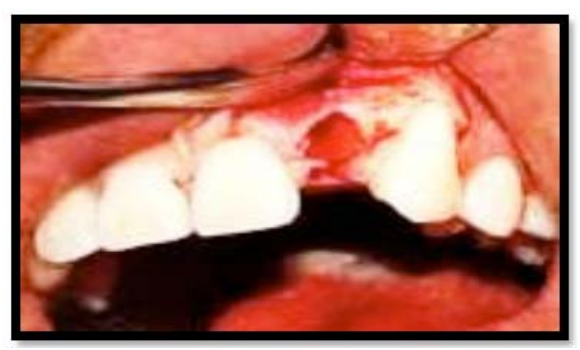

Fig. (2). Proper reflection of the flap should be done to preserve the width of attached gingiva.

If selected extraction is required due to periodontal involvement, internal bevel flaps are necessary part of the extraction procedures, as they permit surgical curettage of diseased sulcular and interproximal soft tissue to expose alveolar bone for the correction of any associated morphologic or pathologic osseous defects.

\section{PARTIALLY IMPACTED THIRD MOLAR}

Partially impacted third molar is often complicated by periodontal breakdown of the approximating tooth, so extraction of such teeth should be followed by the treatment of the periodontal lesion. Such treatment includes soft tissue debridement corrects of any Osseous defect and judicious soft tissue replacement and stabilization by careful suturing to avoid aggravating any periodontal disease or creating new periodontal disturbances where none existed before.

- Injudicious use of forceps or elevators during luxation, elevation and extraction may result in crush injuries of the approximating teeth or crushing of the radicular bone of these teeth.

- Inspite of the precautions, if fracture of the alveolar cortical bone occurs then these fractured segments should be repositioned carefully and stabilized with proper sutures, and in many patients such segments remain viable and reattached.

- Occasionally, close root proximity associated with periodontal involvement prevents selected extraction or root amputation. Attempts to correct any inter dental osseous defects and to restore teeth that have close root proximity usually result in undesirable hard and soft tissue contours (reverse architecture).

\section{EXTRACTION OF IMPACTED THIRD MOLARS}

Various clinical studies have described that the extraction of impacted third molars usually results in the formation of vertical detects distal to the second molars [7]. This iatrogenic effect is not related to flap design [8] and occurs commonly when third molars are extracted in individuals older than 25 years [7]. Other factors that appear to play a role in the development of lesions on the distal surface of second molars, particularly in those older than 25 years, include the presence of visible plaque, bleeding on probing, root resorption in the contact area between second and third molars, presence of a pathologically widened follicle, inclination of the third molar, and proximity of the third molar to the second molar [9].

\section{CONCLUSION}

Exodontia is associated with many possible complications. Tooth extraction at all times may not be the best treatment option. Before the tooth is extracted the other options (e.g. endodontics) must be considered in the best interest of the patient. The divergent root morphology of teeth necessitates a selection of well maintained, modern instruments, used with the accurate techniques, to avoid excessive trauma to the patient.

\section{CONFLICT OF INTEREST}

The authors confirm that this article content has no conflict of interest.

\section{ACKNOWLEDGEMENTS}

Declared none. 


\section{REFERENCES}

[1] Niedzielska I, Kowol I, Sroczynska-Grula A. Iatrogenic injury during extraction of lower molar teeth. Dent Med Probl 2009; 46: 501-5.

[2] Thorn JJ, Mogeltoft M, Hansen PK. Incidence and aetiological pattern of jaw fractures in Greenland. Int J Oral Maxillofac Surg 1986; 15: 372-9.

[3] Krimmel M, Reinert S. Mandibular fracture after third molar removal. J Oral Maxillofac Surg 2000; 58: 1110-12.

[4] Subhashraj K, Ramkumar S, Ravindran C. Pattern of mandibular fractures in Chennai, India. Br J Oral Maxillofac Surg 2008; 46: $126-7$.
Szucs A, Bujtar P, Sandor GKB, Barabas J. Finite element analysis of the human mandible to assess the effect of removing an impacted third molar. J Can Dent Assoc 2010; 76: a72.

[6] Neelima AM. Textbook of oral maxillofacial surgery. $2^{\text {nd }}$ ed. New Delhi, India: Jaypee Brothers 2008.

[7] Ash M, Costich E, Hayward J. A study of periodontal hazards of third molars. J Periodontol 1962; 33: p. 209.

[8] Chin Quee T, Gosselin I, Millar L. Surgical removal of the fully impacted mandibular third molar: the influence of flap design and alveolar bone height. J Periodontal 1985; 56: 625-30.

[9] Kugelberg C. Third molar surgery. Curr Open Dent 1992; 2: 9-16.

Received: December 22, 2014

Revised: March 04, 2015

Accepted: March 10, 2015

(C) Rajan et al.; Licensee Bentham Open.

This is an open access article licensed under the terms of the Creative Commons Attribution Non-Commercial License (http://creativecommons.org/licenses/by-nc/3.0/) which permits unrestricted, non-commercial use, distribution and reproduction in any medium, provided the work is properly cited. 